\title{
ENTRE O DISCURSO E A ONTOLOGIA DO SER SOCIAL: POSSIBILIDADES DE UM DEBATE
}

\section{LAURENIO LEITE SOMBRA ${ }^{1}$}

RESUMO: O objetivo deste artigo é fazer um contraponto entre a teoria do discurso de Ernesto Laclau e Chantal Mouffe e a ontologia do ser social de Lukács. Tentamos expor que a dualidade estabelecida por Laclau e Mouffe entre contingência e necessidade, categorias fundamentalmente lógicas, não abarca a ontologia do ser social, que constitui uma objetividade que "tem a sua própria lógica", nem da necessidade nem da contingência. Lukács, assim como Marx, parte do trabalho como categoria central da passagem de uma ontologia da natureza para a ontologia do ser social. Aqui se argumenta que a linguagem tem o mesmo peso ontológico do trabalho. Inserindo-se essa dimensão na ontologia de Lukács, alguns dos elementos da teoria do discurso de Laclau e Mouffe, apesar de suas insuficiências, podem ser repensados.

PALAVRAS-CHAVE: Lukács; Laclau e Mouffe; Discurso; Ontologia do ser social.

ABSTRACT: The aim of this paper is to make a counterpoint between the discourse theory of Ernesto Laclau and Chantal Mouffe and Lukács'ontology of social being. We try to show that the duality established by Laclau and Mouffe between contingency and necessity, fundamentally logical categories, does not encompass the ontology of social being, which constitutes an objectivity that "has its own logic", neither of necessity nor of contingency. Lukács, like Marx, starts from labor as the central category of the shift from an ontology of nature to the ontology of social being. Here it is argued that language has the same ontological weight than labor. Inserting this dimension into Lukacs' ontology, some of the elements of Laclau and Mouffe's discourse theory, despite their shortcomings, can be rethought.

KEYWORDS: Lukács; Laclau and Mouffe; Discourse; Ontology of social being.

Em 1985, Ernesto Laclau e Chantal Mouffe, dois autores que já apresentavam um currículo respeitado de pesquisas no âmbito marxista, publicam em conjunto Hegemonia e estratégia socialista. O livro, influenciado por uma teoria do discurso pós-estruturalista, fazia profundas críticas ao pensamento marxista desenvolvido ao longo do século XX e inaugurava o que se costumou chamar de "pós-marxismo". Nele, são discutidos e criticados vários aspectos teóricos do marxismo, como a primazia da classe proletária como classe revolucionária, a relação de determinação entre infraestrutura e superestrutura, bem como a própria ideia de uma necessidade histórica de superação do capitalismo e emergência do socialismo. Em seu lugar,

\footnotetext{
${ }^{1}$ Professor Adjunto de Filosofia da Universidade Estadual de Feira de Santana (UEFS). Doutor em Filosofia pela Universidade Federal da Bahia (UFBA). E-mail: lausombra@hotmail.com.
} 
os autores inseriam uma nova gramática filosófica que, a partir da contingência do discurso, reformulava categorias para as lutas políticas, a articulação entre grupos sociais heterogêneos e a resistência comum a grupos opressores, na luta por uma "democracia radical".

O livro rapidamente provocou reações fortes, sendo a revista New Left Review um local privilegiado para alguns debates importantes que ocorreram. Em 1987, o pensador britânico Norman Geras publicou um artigo fortemente crítico ao livro, merecendo uma resposta no mesmo ano de Laclau e Mouffe. No ano seguinte, Geras fez outro artigo talvez ainda mais crítico, como tréplica. No mesmo ano, o acadêmico grego Nicos Mouzelis também publicou um artigo que, sem perder a posição crítica, já traz mais nuances do que a avaliação de Geras. Outras discussões críticas se sucederam, mas as citadas, feitas ainda na década de publicação do livro, já apontam para questões fundamentais a serem avaliadas.

Posteriormente, o livro de Laclau e Mouffe ganharia um alento renovado com a queda do muro de Berlim, o avanço do neoliberalismo e a multiplicação de grupos de resistência em contraposição a conservadores e reacionários, ambos os lados cada vez menos associados à clássica divisão entre burgueses e proletários. Nesse processo, tornava-se ainda mais necessária uma rediscussão dos fundamentos do livro de Laclau e Mouffe, a partir de alguns elementos do pensamento marxista, e é o que se tenta fazer nesse artigo.

A hipótese, aqui, é que a ontologia do ser social, desenvolvida por Marx e formalizada filosoficamente pela obra do Lukács tardio, tem uma importante contribuição nesse debate, desde que acrescido o devido relevo à questão da linguagem, base fundamental para os fatores discursivos abordados por Laclau e Mouffe. Com estes aspectos, defende-se, dualidades como necessidade-contingência, necessidade-liberdade, atividade material-atividade discursiva e lógica-ontologia podem ser pensadas a partir de um padrão mais rico de análise, propiciando subsídios importantes para a filosofia e as ciências sociais, especialmente a teoria política.

\section{A contingência do discurso e a luta política}

No livro Hegemonia e estratégia socialista, Laclau e Mouffe analisam, em dois longos capítulos, o desenvolvimento histórico do conceito de hegemonia, defendendo a tese de que ele foi concebido para suturar uma inadequação do próprio pensamento marxista: a contraposição entre a fragmentação das lutas e dos grupos políticos populares, de um lado, e uma teoria que supostamente essencializava a classe proletária industrial como a classe necessariamente revolucionária, do outro. 
No capítulo 3, o mais propositivo e possivelmente o mais importante do livro, os autores reformulam o conceito gramsciano de hegemonia a partir de uma teoria discursiva influenciada pelo conceito de sobredeterminação de Althusser, mas acima de tudo por formulações pósestruturalistas de Pêcheux, Derrida e (principalmente) Michel Foucault. A teoria formulada certamente ainda traz influências estruturalistas, que rejeitam uma matriz ontológica do discurso e o associam a um sistema de diferenças. Ao mesmo tempo, é recusado um fechamento lógico desse sistema de diferenças. Os autores falam no "caráter incompleto, aberto e politicamente negociável de toda identidade" (LACLAU; MOUFFE, 2015, p. 177).

Para eles, as organizações sociais decorrem de uma prática articulatória, e esta é configurada por uma estrutura discursiva, sempre tensa, aberta e politicamente negociada. A estrutura discursiva é articulatória porque visa fixar e articular "elementos" com os quais se depara. Segundo os autores, "qualquer prática que estabeleça uma relação entre elementos de tal modo que a sua identidade seja modificada como um resultado da prática articulatória, chamaremos discurso" (LACLAU; MOUFFE, 2015, p. 177). Assim, o próprio conceito de discurso está associado a uma prática que articula "elementos" e os configura, produzindo uma nova realidade simbólica, sempre disputada, por sua vez constituindo novas práticas.

Esta nova realidade simbólica é pensada a partir da apropriação de Althusser do conceito psicanalítico de sobredeterminação. O filósofo francês desenvolveu o conceito em seu livro Pour Marx, tentando contrapor-se ao conceito de contradição em Hegel, que ele ainda considerava excessivamente simplista.

Quando (...) entram em jogo, no mesmo jogo, uma prodigiosa acumulação de "contradições", algumas das quais radicalmente heterogêneas, e não tendo todas a mesma origem nem o mesmo sentido, nem o mesmo nível e local de aplicação, e que, entretanto, "se fundem" em uma unidade de ruptura, não é mais possível falar da única virtude simples da "contradição" geral (ALTHUSSER, 1979, p. 86).

Com este conceito, Althusser sugere uma maior complexidade na relação entre as várias instâncias que configuram o mundo social, incluindo aquelas que delimitam as relações de produção, bem como as instâncias legais e ideológicas. Ele não rejeita a primazia da "base" das relações de produção, que vê como "condição de existência" do processo, mas sugere uma participação mais determinante de "cada uma das instâncias em jogo", que "não se 'dissipam' como um puro fenômeno na unidade interior de uma contradição simples" (ALTHUSSER, 1979, p. 86). Assim:

A "contradição" é inseparável da estrutura do corpo social total no qual ela se exerce, inseparável de suas condições formais de existência, e das instâncias mesmas que governa, que ela própria é, portanto, no seu coração, afetada por elas; determinante, mas também determinada em um único e mesmo movimento, e determinada pelos diversos níveis e pelas diversas instâncias da formação social que ela anima; poderíamos dizer sobredeterminada em seu princípio" (ALTHUSSER, p. 1979, p. 87). 
Para além dessa noção trazida por Althusser, interessa especialmente a Laclau e Mouffe a origem simbólica do conceito, desde Freud. Segundo os autores, a sobredeterminação freudiana "é um tipo bastante preciso de fusão que envolve uma dimensão simbólica e uma pluralidade de significados. O conceito de sobredeterminação é constituído no campo do simbólico e não tem qualquer sentido fora dele" (LACLAU; MOUFFE, 2015, p. 169).

Como o social é constituído no âmbito do simbólico, e este é sempre frágil e contingente, os autores concluem pela permanente instabilidade e precariedade do social. Este cria uma realidade sobredeterminada na qual perde o sentido qualquer dualidade entre essência (supostamente, a base material) e aparência (a base ideológica e as instituições).

Não há dois planos, um das essências e o outro das aparências, uma vez que não há possibilidade de se fixar um sentido literal último em relação ao qual o simbólico seria um plano segundo e derivado de significação. A sociedade e os agentes sociais carecem de qualquer essência, e suas regularidades consistem meramente de formas relativas e precárias de fixação que acompanham o estabelecimento de uma certa ordem. (LACLAU; MOUFFE, 2015, p. 169).

É esta precariedade e contingência que marcará a teoria de Laclau e Mouffe. Se o social é constituído neste contexto ao mesmo tempo prático e simbólico, ele decorre das lutas políticas antagônicas que disputam a sua fixação sob uma determinada perspectiva.

A impossibilidade de uma fixação última de sentido implica que deve haver fixações parciais (...). Mesmo para que se possa diferir, subverter o sentido, há de haver um sentido. Se o social não consegue fixar a si mesmo, (...) o social só existe, no entanto, como um esforço para construir esse objeto impossível. Qualquer discurso se constitui como tentativa de dominar o campo das discursividades, de deter o fluxo das diferenças, de construir um centro. Chamaremos os pontos discursivos fundamentais privilegiados desta fixação de pontos nodais (LACLAU; MOUFFE, 2015, p. 187).

As próprias identidades sociais são conformadas como resultado dessas disputas. Aqui, há um elemento fundamental de questionamento à base ontológica das classes sociais, visto que mesmo elas decorrem, segundo a perspectiva de Laclau e Mouffe, da disputa política e simbólica que decorre do caráter contingente do social. Não é possível uma definição das classes burguesa ou proletária, ou mesmo de grupos sociais como negros, indígenas, gays, mulheres, pacifistas, verdes, conservadores, evangélicos, neonazistas etc., muito menos a primazia de um deles, sem a compreensão dos processos de fixação que permitem que eles existam e que os colocam em determinada posição na luta política. Em um livro posterior, Laclau afirma que a constituição da identidade é um ator de poder. E complementa:

toda objetividade é uma objetividade ameaçada. Se apesar disso ela logra afirmar-se parcialmente como objetividade, isto só pode ser dado sobre a base de reprimir aquilo que a ameaça. Estudar as condições de existência de certa identidade social é equivalente, portanto, a estudar os mecanismos de poder que a tornam possível (LACLAU, 2000, p. 48).

A luta por hegemonia se transforma quando vista a partir desta precariedade mais basilar. As reflexões marxistas do final do século XIX e acima de tudo da primeira metade do século XX em torno deste conceito partiam, frequentemente, da necessidade de 
complementação da perspectiva clássica que atribuía uma primazia burguesa na revolução capitalista e uma primazia proletária na superação do capitalismo. Para além dessa primazia, teóricos marxistas perceberam a necessidade de articulação entre classes, diante de fatores empíricos que não se coadunavam perfeitamente com as determinações fundamentais da teoria. Assim, desde o século XIX, Plekhanov argumentava que "a burguesia na Rússia era ainda demasiado débil para tomar a iniciativa na luta contra o czarismo: a classe trabalhadora deveria tomar à frente da revolução democrático-burguesa" (apud ANDERSON, 1991, p. 30). Mais tarde, falou na "primazia do proletariado na revolução burguesa na Rússia" (apud ANDERSON, 1991, p. 31). Esta formulação, ao seu modo, foi abraçada por bolchevistas e mencheviques no século XX, e desenvolvida por Lenin. Para este, o proletariado é a "única classe consistentemente revolucionária da sociedade contemporânea" e "deve ser a dirigente na luta de todo o povo por uma revolução totalmente democrática (...) contra os opressores e exploradores" (apud ANDERSON, 1991, p. 31). Nos textos do Kominterm após a revolução russa, por sua vez, "o dever do proletariado era exercer a hegemonia sobre os outros grupos explorados que eram seus aliados de classe na luta contra o capitalismo" (ANDERSON, 1991, p. 35). Gramsci seguiu nessa linha, mas trazendo a novidade de destacar a importância do fator de consenso, para além de possíveis relações de coerção. Assim, ele defendia "a ascendência cultural que deveria demonstrar a hegemonia do proletariado sobre as demais classes aliadas" (ANDERSON, 1991, p. 37).

Na perspectiva de Laclau e Mouffe, ao contrário, não era possível definir previamente como seria feita a articulação de grupos sociais populares, nem a primazia de um deles. Não seria sequer possível definir logicamente um ponto em comum entre cada um dos agentes que permitisse essa articulação. Eles pensam esta possibilidade frequentemente se dando na prática a partir da resistência a um grupo antagônico comum, por meio de "relações de equivalência" entre os grupos sociais que buscarão se articular. Esta equivalência funciona, segundo os autores, como uma "transposição metafórica", ou seja, uma tentativa de articulação entre formas sociais que não são logicamente articuláveis. A equivalência se daria por oposição "entre diferentes setores de classe num espaço social dividido em dois campos antagonísticos" (LACLAU; MOUFFE, 2015, p. 184).

Todas estas formulações de Laclau e Mouffe, baseadas no caráter simbólico do mundo social, suscitam certa pecha de idealismo. O mundo objetivo, por vezes, parece submerso numa imensa e precária cadeia discursiva. Mas os autores rejeitam, antecipadamente, esta acusação. É fundamental, defendem, se compreender o caráter material, não mental, de toda estrutura 
discursiva. Para eles, por exemplo, "a prática da articulação (...) deve (...) atravessar toda a densidade material da multiplicidade de instituições, rituais e práticas através das quais uma formação discursiva é estruturada" (LACLAU; MOUFFE, 2015, p. 182-183).

Os autores afirmam que "todo objeto é constituído como objeto de discurso, uma vez que nenhum objeto é dado fora de condições discursivas de emergência" (LACLAU; MOUFFE, 2015, p. 180). Naturalmente, é uma afirmação que volta a suscitar a acusação de idealismo. Mas eles explicam:

Um terremoto ou a queda de um tijolo é um evento que certamente existe (...) independente da minha vontade. Mas, se sua especificidade como objeto será constituída seja em termos de um 'fenômeno natural' ou como 'expressão da ira de Deus', vai depender da estruturação de um campo discursivo. O que se nega não é que tais objetos existam externamente ao pensamento, mas antes a afirmação bastante diferente de que eles próprios possam se constituir como objetos fora de qualquer condição discursiva de emergência. (LACLAU; MOUFFE, 2015, p. 181).

Neste sentido, a própria diferenciação entre discursivo e extradiscursivo é colocada entre parênteses. De um lado, porque o que chamamos de "extradiscursivo" só pode participar da vida social justamente porque apropriado em um discurso. Por outro lado, porque o discurso não vaga isolado, abstratamente, mas numa prática material que lida com a realidade, "se choca" com o chão áspero da prática. A própria definição anteriormente formulada de discurso como "articulação de elementos" remete a essa realidade.

A definição de elemento é bastante lacônica. Os autores o apresentam como "toda diferenciação não discursivamente articulada" (Laclau e Mouffe, 2015, p. 178). Estamos, portanto, diante de uma definição negativa. Elemento é "algo" que ainda não foi apropriado pelo discurso, e os autores não investigam esse "algo". Mas a sua existência é fundamental, pois é justamente a constatação de que há aspectos não apropriados pelo discurso que fazem com que ele não se encerre, tenha sempre uma natureza precária. Para eles, "se a contingência e a articulação são possíveis, é porque nenhuma formação discursiva é uma totalidade suturada, e a transformação dos elementos em momentos [“elementos" apropriados pelo discurso] nunca é completa" (LACLAU; MOUFFE, 2015, p. 180).

\section{Pós-marxismo criticado}

Como afirmado anteriormente, o livro de Laclau e Mouffe recebeu uma série de críticas, especialmente a partir do artigo de Norman Geras em 1987, na New Left Review. Uma primeira crítica de Geras é, como seria de se prever, ao suposto idealismo de Laclau e Moufe. Segundo Geras, é chocante a visão dos autores de que "não há objetividade pré-discursiva da realidade" (GERAS, 1987, p. 66). Mesmo quando, na réplica, Laclau e Mouffe protestam contra a incompreensão de Geras, este pontua, no seu segundo artigo, com uma pequena concessão: "os 
autores afirmam a existência dos objetos externos ao pensamento, mas o resto do que eles dizem cancela esta afirmação, a retiram de qualquer peso teórico" (GERAS, 1988, p. 55).

Na réplica de Laclau e Mouffe a Geras, eles fazem uma distinção entre ser e existência. $\mathrm{Na}$ linguagem deles, seria idealista rejeitar a existência das coisas antes da linguagem, o que não é o caso. Mas os autores entendem que o "ser", ao contrário da existência, só pode ser pensado no discurso. Um ponto curioso, a partir daí, é a rejeição da própria exigência de Geras a uma objetividade pré-discursiva. Os autores respondem a isso com uma analogia: "é equivalente a perguntar a um materialista pelas condições de possibilidade da matéria, ou para um teísta pelas condições de possibilidade de Deus" (LACLAU; MOUFFE, 1987, p. 86). A analogia é bastante reveladora da visão dos autores porque, tal como a matéria para um materialista e Deus para um teísta, eles rejeitam a investigação filosófica de "algo" aquém do discurso. É nesse sentido que os "elementos", cuja existência eles reconhecem, só podem ser pensados negativamente, jamais efetivamente conceituados. Como o elemento é definido como "toda diferenciação não discursivamente articulada", a sua condição, por definição, não poderia ir além dessa negatividade na linguagem forjada pelos autores.

Mas Geras vê outro pecado importante na obra de Laclau e Mouffe. Para ele, falta ao livro uma "direção prático-normativa" (GERAS, 1987, p. 69). E esta carência tem direta correlação com o que ele vê de uma falta de substância teórica na obra, que retira do mundo social toda objetividade possível.

\begin{abstract}
A sugestão (...) de que não haver uma relação mais forte entre o socialismo e a classe trabalhadora do que a relação entre o socialismo e qualquer outra seja um idealismo - ou uma indeterminação, se preferir - corre livre [run wild]. (...) Seria possível supor que discursos e lutas feministas não têm mais conexão particular com certo tipo de agente social do que com outro? Ou eles não concernem e envolvem especialmente as mulheres, fonte básica da sua existência e do seu vigor? E isto não se dá em consequência de dispositivos objetivos da posição social e econômica das mulheres? Aqui como noutros campos, estruturas e determinantes materiais conformam e limitam o que a prática política pode 'construir'. Se o socialismo ainda é visado, momento interno da revolução democrática ou não, então a relação específica de exploração, que é definitiva do que o capitalismo é, tem de ser abolida; e é mera fantasia pensar que o agente social subordinado por esta relação poderia não ser central para esta abolição (GERAS, 1987, p. 81).
\end{abstract}

Aqui parece se concentrar o eixo central da crítica de Geras. A contingência e precariedade do discurso na teoria de Laclau e Mouffe parecem retirar qualquer condição objetiva das relações sociais e dos grupos sociais explorados. Assim fazendo, tornam voluntaristas as práticas políticas, produto de uma pletora de escolhas sem nenhum fundamento último minimamente consolidado que as anteceda.

Laclau e Mouffe, em sua resposta, rejeitam a tentativa de objetivação última, especialmente aquela que se baseia nos fundamentos econômicos, mesmo quando, como reconhecem Geras e outros pensadores marxistas, as outras instâncias tenham uma autonomia 
relativa. Para Laclau e Mouffe, "os conceitos de 'determinação em última instância' e 'autonomia relativa' são logicamente incompatíveis" (1987, p. 93), sendo necessário rejeitar como um todo a própria categoria da determinação. E complementam: "não há última instância sobre cuja base a sociedade pode ser reconstruída como uma estrutura racional e inteligível, mas (...) a eficácia relativa de cada esfera depende de uma relação estável entre forças antagonistas que penetram inteiramente no social" (LACLAU; MOUFFE, 1987, p. 94).

Em relação à direção prático-normativa, Laclau e Mouffe afirmam que a própria lógica da contingência sugere uma perspectiva democrática e não autoritária, exatamente o oposto de uma visão "fundacional". "Para nós, a articulação entre o socialismo e a democracia, longe de ser um axioma, é um projeto político; ou seja, é o resultado de uma longa e complexa construção hegemônica, que está permanentemente sob ameaça e precisa ser continuamente redefinida" (LACLAU; MOUFFE, 1987, p. 101). E complementam: "a primeira condição de uma sociedade radicalmente democrática é aceitar o caráter contingente e radicalmente aberto de todos os seus valores - e, nesse sentido, abandonar a aspiração por uma fundação única" (LACLAU; MOUFFE, 1987, p. 102).

Geras, em sua tréplica, recusa a associação de um pensamento democrático à contingência radical de Laclau e Mouffe. Para ele, a perspectiva democrática não pode e não deve abdicar de uma consistência científica. "Diferente da fé ou do dogma, o conhecimento genuíno é sempre provisório, sujeito a revisão à luz de nova informação e evidência, necessitando periodicamente de ser reestruturado, [por ser] falível" (GERAS, 1987, p. 59). Por outro lado, ele afirma, "não há nada de democrático (...) em uma perspectiva que mergulha estas matérias em total arbitrariedade e irracionalismo" (GERAS, 1987, p. 59).

Outros aspectos deste debate poderiam ser abordados: por exemplo, na tréplica Geras mostra como Laclau e Mouffe simplificam a ideia de determinação em Marx, que usou vários termos para abordar este conceito, com conotações diferentes (correspondência, condicionamento ou a própria determinação). Simplificação que aumenta ao desconsiderar o longo debate marxista em torno dessa ideia. "A história subsequente do marxismo poderia ser escrita como uma longa meditação, com reais diferenças internas sobre isso, sobre a exata natureza, o escopo e a força desta relação" (GERAS, 1988, p. 39). A sua crítica vem acompanhada do abismo que Laclau e Mouffe parecem criar entre determinação e contingência, aparentemente exigindo uma disjuntiva fundamental em sua formulação. "Por que não há espaço lógico entre 'o mais extravagante reducionismo econômico' e a mera 'pluralidade'? Por que não há espaço para uma noção de primazia explanatória?” (GERAS, 1988, p. 39). 
Mouzelis, no mesmo ano e na mesma revista, também parece rejeitar uma leitura disjuntiva das polêmicas estabelecidas por Laclau e Mouffe. Por outro lado, ao contrário de Geras, ele afirma, em prol dos autores, que eles não identificam discurso com linguagem, identificação que reforçaria a acusação de idealismo. Mas pondera: "eu concordo com suas visões de que todos os arranjos institucionais (...) são discursivamente construídos. Mas não há absolutamente uma razão para associar construção linguística com fragilidade e precariedade" (MOUZELIS, 1988, p. 113-114).

Se a distinção entre necessidade/objetividade e contingência/luta política pode ser aproximada da clássica distinção sociológica entre estrutura e agência, Mouzelis também faz uma análise mais nuançada nesse campo. Ele reconhece que nem todos os autores marxistas fizeram o devido balanço entre esses elementos, frequentemente caindo em extremos: "teorias de classe ultra-voluntaristas que terminam explicando todo o desenvolvimento social em termos de maquinações maquiavélicas da classe dominante" ou "teorias que intensificam injunções estruturais e contradições a tal ponto que os atores são reduzidos a meros "portadores de estrutura" (MOUZELIS, 1988, p. 112). Apesar disso, Laclau e Mouffe não parecem ter encontrado uma solução mais adequada à dicotomia: "a desconsideração da distinção entre agência/estrutura institucional - que encontramos não apenas no trabalho de Laclau e Mouffe, mas em vários discursos estruturalistas e pós-estruturalistas - cria mais problemas do que resolve" (MOUZELIS, 1988, p. 113).

\section{Ontologia do ser social: possibilidades a partir de Marx e Lukács}

As críticas de Geras e Mouzelis parecem apontar para alguns fatores importantes em relação ao "pós-marxismo" de Laclau e Mouffe: certa perda de objetividade teórica, falta de direção prático-normativa (em alguma medida) e, principalmente, uma aparente simplificação dos profundos e extensos estudos marxistas, com diversos e qualificados debates internos. É a partir destes aspectos críticos que a ontologia do ser social formulada por Lukács a partir da obra de Marx permite algumas reflexões importantes sobre o debate, principalmente se receber o devido aporte linguístico/discursivo, como se verá mais adiante.

Lukács promove, em sua obra madura, uma espécie de retorno à ontologia. Isso significa, antes de tudo, o reconhecimento da necessidade de se partir da fundamentação de uma realidade que nos ultrapassa. Algo aparentemente trivial, mas que os longos anos de primazia do cogito cartesiano sobre a realidade ou, mais ainda, do fenômeno kantiano sobre a "coisa-emsi”, exige que seja resgatado. O ser humano, é verdade, se constitui em um mundo social que 
lhe é próprio, mas esta constituição é antecedida pela própria noção inexorável de natureza. Se em Laclau e Mouffe, esta temática é praticamente inexistente, Lukács a toma como base, seguindo os passos de Marx. O filósofo húngaro recupera uma frase de Horácio, "naturam expellas furca, tamen usque recurret" [ainda que expulses a natureza com o forcado, ela sempre voltará] (apud LUKÁCS, 2018, p. 69), para reforçar sua posição.

Esta constatação ontológica não pode ser confundida, em Lukács, com o processo interpretativo que a ciência lança sobre a própria realidade. Segundo ele,

o desenvolvimento do pensamento mostra que as questões ontológicas afloram muito antes da possibilidade de serem respondidas cientificamente, que tal desenvolvimento elimina passo a passo as falsas concepções para substitui-las por outras mais corretas e que, desse modo, surge uma ininterrupta interação com a ciência. (LUKÁCS, 2018, p. 71).

Ou seja: há interação entre ontologia e epistemologia, mas não uma identificação entre ambas. Poderíamos dizer que a plena identificação representaria o auge do positivismo, numa perspectiva sob a qual os "fatos" científicos seriam sempre tratados como a realidade última; mas a plena desidentificação produziria um ceticismo relativista, que impediria que as formulações ontológicas fossem transformadas pelo avanço da ciência. Lukács se preocupava especialmente com o segundo tipo, exemplificado pela "dupla verdade" do cardeal Berlarmino no século XVII, que, diante de estudos científicos como o de Galileu, não aceitava que estes pudessem abalar os fundamentos ontológicos da verdade revelada, no máximo "salvar as aparências". Para o pensador húngaro, esta perspectiva, com nova roupagem, se desenvolveu na modernidade com pensadores como Berkeley e Kant, que buscaram "demonstrar gnosiologicamente que não é possível atribuir significado ontológico aos nossos conhecimentos do mundo material" (2018, p. 39); passa por pensadores do século XIX, como Nietzsche e Bergson; e chega a correntes diametralmente opostos do século XX, como o neokantismo, a fenomenologia e o neopositivismo. Este último abarca grandes avatares da "dupla verdade" ou, mais precisamente, da rejeição cabal da ontologia. "Trata-se [o neopositivismo] da forma mais pura que se tem até hoje da teoria do conhecimento fundada sobre si mesma (...). Somente quando o em-si foi declarado teoricamente inapreensível, a teoria do conhecimento tornou-se autônoma" (LUKÁCS, 2018, p. 58).

É em oposição a esta perspectiva consolidada pela modernidade sob diversos matizes que Lukács reafirma o ontológico, partindo da constatação inexorável da natureza. Para o filósofo húngaro, contudo, a ontologia precisa alcançar o mundo social, as categorias explicativas da natureza não são suficientes. A ideia de um ser social como tal começa a ser assumida de forma concreta por Marx, desde suas concepções de juventude. Nos Manuscritos, o pensador alemão já mostra claramente o papel fundamental da natureza, mas também a 
transformação que a condição humana promove em seu modo particular de lidar com ela. "O homem não é apenas ser natural, mas ser natural humano, isto é, ser existente [seiendes Wesen] para si mesmo, por isso ser genérico que, enquanto tal, tem de atuar e confirmar-se tanto em seu ser quanto em seu saber" (MARX, 2010, p.128).

Esta interação particular do ser humano com a natureza só é possível pela inserção fundamental da categoria do trabalho como dobradiça genética na passagem de uma ontologia da natureza para uma ontologia do ser social. "O trabalho dá lugar a uma dupla transformação. Por um lado, o próprio ser humano que trabalha é transformado por seu trabalho (...). Por outro lado, os objetos e as forças da natureza são transformados" (LUKÁCS, 2018, p. 286). Este processo tem um tipo particular e imanente de "teleologia", já que decorre sempre de uma ação humana que projeta ideais, um modo de transformação que antecede a própria atividade.

Um ponto fundamental que Lukács enfatiza, na apropriação do pensamento de Marx, é que este processo propicia novas objetividades, não encontradas como tais numa ontologia da natureza.

As formas de objetividade do ser social se desenvolvem à medida que a práxis social surge $\mathrm{e}$ se explicita a partir do ser natural (...). Esse desenvolvimento, todavia, é um processo dialético, que começa com um salto, com o pôr teleológico no trabalho, para o qual não pode haver nenhuma analogia na natureza (LUKÁCS, 2018, p. 287).

Estas definições já suscitam algumas questões essenciais em torno da teoria marxista. O fato de que a ontologia do ser social parte, geneticamente, do trabalho explica a ênfase que se dá ao "econômico" na obra de Marx. Contudo, bem compreendida a articulação inelutável do trabalho com o processo humano de idealização, torna-se impossível qualquer separação simplista com o mundo da consciência e da produção de valores. "Toda práxis, mesmo a mais imediata e a mais cotidiana, contém em si essa referência ao ato de julgar, à consciência, etc., visto que é sempre um ato teleológico" (LUKÁCS, 2018, p. 317). Por outro lado, "o agir social, o agir econômico dos homens, abre livre curso para forças, tendências, objetividades, estruturas etc. que nascem decerto exclusivamente da práxis humana, mas cujo caráter resta, no todo ou em grande parte, incompreensível para quem o produz" (LUKÁCS, 2018, p. 318).

Apesar das novas objetividades constituídas, esta ontologia emergente coloca uma abertura do ser social que não se encontra no ser natural. O ser social sempre se apresenta sob o signo da alternativa, de possibilidades que não estão dadas previamente. É fundamental para a filosofia de Lukács a contraposição desses dois elementos: de um lado, certa objetividade social que propicia relações teoricamente analisáveis de causa e efeito; de outro, a percepção de que estas relações nunca são plenamente determinadas, porque a sua condição remete a alternativas e à nossa própria condição de sujeitos. 
Embora todos os produtos do pôr teleológico surjam e operem de modo causal, (...) eles têm a peculiaridade puramente social de se apresentarem com o caráter de alternativa (...). Essa alternativa, por mais cotidiana e superficial que seja, (...) constitui, no entanto, uma alternativa autêntica, porque abriga em si (...) a possibilidade de retroagir sobre seu sujeito para transformá-lo (LUKÁCS, 2018, p. 343).

Estes aspectos apresentados remetem à contraposição permanente entre determinação e liberdade que configura o próprio complexo social. "Toda decisão alternativa constitui o centro de um complexo social que conta com a determinidade e a liberdade entre os seus componentes dinâmicos" (LUKÁCS, 2013, p. 140). Essa contraposição, contudo, não pode ser embasada em uma articulação lógica entre determinação e liberdade, como frequentemente aparece na dialética hegeliana. Lukács critica claramente o que poderíamos chamar de um "pan-logicismo" da filosofia de Hegel, especialmente na Ciência da lógica. Sob a perspectiva hegeliana, a ontologia se subordina a um grande mecanismo lógico, destinado, teleologicamente, a integrar sujeito e objeto numa articulação cada vez mais perfeita entre liberdade e necessidade, tendo como horizonte ou "causa final" a noção metafísica de Espírito Absoluto. Com isso, o conhecimento da realidade é apreendido como um grande e inexorável mecanismo de dedução lógica.

Se, como ocorre em Hegel, a lógica for entendida como fundamento teórico da ontologia, é inevitável que as deduções lógicas sejam vistas como as próprias formas da gênese ontológica. Com isso, a hierarquia lógica sistemática passa a constituir a base do método, mediante o qual se percorre obrigatoriamente o caminho - ontológico - para a autorrealização da identidade de sujeito e objeto (LUKÁCS, 2018, p. 223).

Recusar esta perspectiva é recusar que exista uma determinação lógica anterior à ontologia. Para Lukács, “os fatos possuem sua própria lógica - nem sempre formal” (LUKÁCS, 2018, p. 59). Isto vale para outras construções, como a matemática e a geometria, que apenas “constituem espelhamentos, e não partes nem 'elementos' da realidade física" (LUKÁCS, 2018, p. 65). Partir do ontológico, e não do lógico, significa antes de tudo rejeitar uma necessidade última na concepção do mundo real. O próprio conceito de necessidade, nesse sentido, remete a uma categoria lógica que, como instância primária, não é admitida por Lukács. Isto significa que o processo dialético decorrente do ser social sempre deve considerar as “impurezas" de uma objetividade ontológica que, ao mesmo tempo, é carregada de interstícios e, no caso do ser social, do próprio espaço ontologicamente inscrito da liberdade. Não é possível, a priori, associar cada singularidade da vida concreta a um elemento da "totalidade", numa determinação lógica perfeita.

Em Laclau e Mouffe, também há esta recusa da necessidade lógica enquanto categoria primária. Ocorre que, na sua recusa, lançam mão do seu oposto, a categoria igualmente lógica (embora no sentido negativo) da contingência, que pode ser pensada como ausência de necessidade. Para eles, “a necessidade só existe como limitação parcial do campo da 
contingência" (2015, p. 185). Se a contingência é a categoria principal, ela se apresenta com o importante papel crítico de negar, no âmbito social, determinações lógicas na explicação da realidade. Não há uma inexorabilidade na superação do capitalismo, não há classes construídas necessariamente, não há uma consciência de classe que inelutavelmente será adquirida. Todos estes fatores poderão ocorrer, de modo contingente, a partir da luta política e das possíveis articulações discursivas que ela enseja.

A omissão do componente ontológico, contudo, impede que se vislumbrem tendências. Certamente, não é possível a aceitação hegeliana de uma necessidade lógica, mas as objetividades constituídas pelo ser social apontam primazias, possibilidades mais factíveis que outras, todas elas naturalmente passíveis de erro. Mas a omissão das tendências no âmbito do ser social parece remeter todas as possibilidades meramente a um jogo voluntarista decorrente da luta política, sem condições objetivas (não necessárias logicamente, mas ontologicamente reais) que as embasem. A ontologia do ser social, enfim, recusa a simples dualidade entre contingente e necessário, colocando entre estas categorias um jogo complexo de possibilidades, de acordo com o "caráter aproximativo" (LUKÁCS, 2018, p. 367) do conhecimento dialético. É nesse sentido que Geras, como afirmado antes, reivindica um espaço lógico intermediário entre o reducionismo econômico (uma espécie de necessidade lógica no campo dos modos de produção) e as meras pluralidades, espaço de contingência sem delimitações.

\section{Espaços do debate: a ontologia, a linguagem e o antagonismo}

Devemos, então, optar pela ontologia de Lukács em contraposição à teoria discursiva de Laclau e Mouffe? Sem dúvida, a perspectiva ontológica traz um componente de objetividade que permite compreender o mundo social no que este tem de concreto, objetivo, que nos atravessa para além da contingência - sem recair no seu oposto, uma falsa noção de necessidade lógica. No entanto, há alguns limites em sua formulação.

Por exemplo, há uma profunda timidez em abordar a questão dos antagonismos e contradições como elementos fundantes do ser social. Se, na teoria marxista, a luta de classes foi a materialização social mais concreta desses antagonismos e contradições, ela apresenta pouca relevância na formulação de Lukács. Para ele, "as formas de luta de classe possíveis numa formação concreta são, em suas grandes tendências de fundo, rigorosamente determinadas pelas leis gerais da economia” (LUKÁCS, 2018, p. 362-363). Apesar disso, Lukács chega a atenuar a determinação da luta de classes ao econômico pela constatação de que "essa determinação não pode entender-se de maneira adequada até a singularidade" e que 
“as leis econômicas podem se afirmar (...) por caminhos bastante diferenciados, até mesmo opostos, cuja natureza retroage depois sobre a luta de classes" (LUKÁCS, 2018, p. 363). No entanto, não vai muito além disso. Não há uma discussão profunda sobre o papel da luta de classes e dos antagonismos em geral na própria constituição da ontologia do ser social.

Isso pode ser visto também em relação à ideia de contradição. Este conceito, mais do que o da luta de classes, é mencionado em diversos momentos do livro, mas nunca parece assumir um papel explicativo central. Se ele sempre teve, na teoria dialética, um papel negativo fundamental, a sua baixa relevância em Lukács possivelmente se explica em função da sua afirmação de um caráter eminentemente positivo da ontologia.

Quando se traduz um fato da realidade na linguagem da lógica ou da teoria do conhecimento, é evidente que as diferenças que assim se revelam - absolutamente positivas do ponto de vista ontológico - serão expressas na forma de negação. (...) Mesmo assim, cabe notar que a negação só tem condições de expressar as distinções de modo bastante incompleto e indeterminado; por isso, na dialética concreta, o momento da negação deve ser sempre integrado (...) pelo lado positivo (2018, p. 215; grifo meu).

Ocorre que a primazia do positivo no ser social, reivindicação de Lukács, atenua o motor central da dialética, a contradição. Se pensarmos uma visão oposta a essa, com Adorno, "a contradição é o não-idêntico sob o aspecto da identidade; o primado do princípio de nãocontradição na dialética mensura o heterogêneo a partir do pensamento da unidade. Chocandose com os seus próprios limites, esse pensamento ultrapassa a si mesmo" (2009, p. 13). Para o filósofo alemão, em sua Dialética negativa, a dialética só pode ser compreendida numa interação tensa e sempre heterogênea entre a objetividade social e o componente humano que escapa e resiste a ela, a subjetividade. É igualmente equivocado considerarmos uma subjetividade voluntarista que desconsidera as objetividades que a atravessam (aqui diríamos: que desconsidera o ontológico) e uma objetividade que nega a abertura decorrente da subjetividade (que nega a contradição, a negatividade que nele se inscreve). "A subjetividade, o próprio pensamento, não pode ser explicada a partir de si mesmo, mas somente a partir do elemento fático, sobretudo da sociedade; mas a objetividade do conhecimento não é uma vez mais sem o pensamento, sem a subjetividade" (ADORNO, p. 2009, p. 123)2.

Esta perspectiva não nos deve convidar a um afastamento da ontologia do ser social. Deve, apenas, remeter à compreensão da sua complexidade, dos elementos que fazem dela uma

\footnotetext{
${ }^{2}$ Aqui, fazemos apenas algumas ressalvas à formulação de Adorno: (1) parece redutor e desnecessário associar a subjetividade ao "próprio pensamento"; o caráter negativo e resistente da subjetividade humana parece ter uma componente existencial muito mais ampla, que inclui diversos fatores simbólicos, emotivos, corporais etc., do que apenas o pensamento; (2) Com o que aprendemos com Lukács, fica claro que a objetividade social é, antes de ser epistemológica, um fator ontológico; assim, também é redutor afirmá-la apenas como "objetividade do conhecimento". Estas duas restrições não elidem, contudo, a importância da interação dialética formulada por Adorno, sempre heterogênea e sem a perspectiva idealista de uma síntese vindoura.
} 
realidade mais heterogênea, discursivamente disputada, histórica. Para isso, algumas das suas bases devem ser novamente revistas. A hipótese que formulamos aqui é que a ontologia do ser social ganha valor explicativo se repensarmos, nela, o papel da linguagem. Este não deixa de ser formulado por Lukács. Ele afirma, por exemplo, que "é só (...) no ser social, e já em estágios bastante primordiais, no trabalho e na linguagem, que imediatidade e mediações se separam e se unificam, ou seja, que elas aparecem como determinações de reflexões ontológicas" (LUKÁCS, 2018, p. 260; grifo meu).

Na citação acima, trabalho e linguagem são enumerados aparentemente no mesmo nível hierárquico, como base da emergência da ontologia do ser social. Mas Lukács mantém, em seu processo descritivo, a primazia do trabalho, não como anterior cronologicamente na constituição humana, mas conceitualmente. "É claro que a socialidade, a primeira divisão do trabalho, a linguagem etc. surgem do trabalho, mas não numa sucessão temporal claramente identificável, e sim (...) simultaneamente. O que fazemos é, pois, uma abstração sui generis" (2013, p. 44-45). Apesar dessa primazia conceitual, não há uma recusa à interação dialética entre trabalho e linguagem, visto que "no interior desse complexo o trabalho influi continuamente sobre a linguagem e o pensamento conceitual e vice-versa" $(2013$, p. 85).

Mas o que significa, aqui, a linguagem? Acima de tudo, ela é pensada como um elemento fundamental no distanciamento entre sujeito e objeto. Nesse contexto,

Cada signo pode figurar em contextos completamente diferentes. Desse modo, a reprodução realizada através do signo linguístico se separa dos objetos designados por ele e, por conseguinte, também do sujeito que o expressa, tornando-se expressão intelectual de um grupo inteiro de fenômenos determinados, que podem ser aplicados de maneira similar por sujeitos inteiramente diferentes em contextos inteiramente diferentes (LUKÁCS, 2013, p. 127).

Lukács percebe na linguagem "um duplo movimento em direções contrapostas" (2013, p. 222). De um lado, a tendência crescente de generalização, de outro "um movimento oposto na direção de um determinar individualizante, como surgimento de novas palavras ou de novas nuances de significado das palavras já em uso" (2013, p. 222). Mas não desenvolve de modo suficiente esta contraposição. No final, para ele, a linguagem torna-se "imagem e expressão daquilo que o gênero [humano] alcançou faticamente em cada momento de sua autorrealização" (LUKÁCS, 2013, p. 224).

Estas formulações têm extrema importância, mas também apresentam suas limitações. Estas se manifestam, claramente, quando Lukács afirma que "como ocorre com o trabalho, também com a linguagem se consumou um salto do ser natural para o social" (2013, p. 129; grifo meu). Assim, trabalho e linguagem são apresentados teoricamente como dois momentos relativamente independentes, na constituição do ser social. Embora Lukács tenha reconhecido, 
antes, a interação dialética entre os dois fenômenos, não discorre teoricamente sobre a natureza de tal interação.

É relativamente clara a motivação da primazia do trabalho estabelecida por Marx e Lukács. Se a ontologia do ser social parte de uma prévia ontologia natural, o trabalho é exatamente o elemento chave de transição, que permite essa passagem. É fundamental, para o trabalho, o papel da natureza, mas também o papel de um sujeito ativo que permite transformála a partir de uma teleologia imanente, da colocação sempre nova de ideais pelos sujeitos que operam essa transformação. É nesse sentido que o trabalho transforma permanentemente o mundo social e a própria natureza. Desse modo, não seria possível uma ontologia do ser social que desconsiderasse o papel fundamental do trabalho.

Mas o que possibilita o trabalho? Por que há diversos outros animais que reproduzem seu modo de viver a partir da natureza, mas não o fazem a partir de uma categoria como o trabalho? O que permite esta diferenciação, que faz com que, segundo famosa comparação de Marx, "o que distingue, de antemão, o pior arquiteto da melhor abelha é que ele [o arquiteto] construiu o favo em sua cabeça, antes de construí-lo em cera”? (MARX, 1996, p. 298).

Para se compreender melhor esta diferenciação, o trabalho já precisa ser pensado em interação com uma compreensão mais profunda do papel da linguagem na ontologia do ser social. Aqui, alguns aspectos devem ser delimitados. O primeiro remete à grande característica do signo linguístico: a sua capacidade, como sinalizou Lukács, de conduzir a experiência humana para além do contexto imanente de sua atividade. O signo permite um primeiro deslocamento entre sujeito e objeto, que nos projeta a "ir além" (do tempo, do espaço e das possibilidades). Nesse sentido, a projeção de ideais que o próprio trabalho exige está totalmente imbricada com essa possibilidade da linguagem. Mais do que uma projeção psicológica (o que "está na cabeça" do sujeito que trabalha), é fundamental a constituição linguística que a possibilita. $^{3}$

Mas como a linguagem se faz ontologia? A tentativa de estabelecimento de uma relação dicotômica entre linguagem e realidade não nos ajuda aqui. É preciso, ao contrário, compreender, para usar uma imagem do filósofo estadunidense John Austin, como se faz coisas com palavras (AUSTIN, 1990) ${ }^{4}$. Nesse contexto, um segundo aspecto da linguagem a ser ressaltado corresponde aos mecanismos performativos que possibilitam a sua realização na vida

\footnotetext{
${ }^{3}$ Algumas destas formulações já começaram a ser desenvolvidas em textos anteriores (como SOMBRA, 2015, 2018).

${ }^{4}$ Apesar da ênfase compreensível nas palavras, os signos podem ser de outra ordem, como imagens, sons etc.; então, não é possível delimitar a linguagem apenas com as palavras.
} 
concreta das pessoas, e que permitem que ela faça parte cotidiana do nosso modo de significação, nossos afetos, nossas categorias interpretativas, mas acima de tudo que permite que nós construamos um mundo social já em tudo diferente do mundo natural que o antecede. ${ }^{5}$

É fundamental também a compreensão de que a consolidação performativa de um mundo linguístico e social já representa uma profunda relação de poder. É esta relação, mesmo quando mediada pela força silenciosa de uma tradição, que se impõe como algo a ser aceito por um conjunto social, como uma verdade quase não questionada. Os mecanismos performativos pressupõem modos de coerção e estabelecimento de autoridades que se organizam de forma mais ou menos impositiva, mas que podem ser percebidos pela sua capacidade de efetivação nos grupos sociais. Se pensarmos estes mecanismos em articulação com as relações de produção inseridas pelo mundo do trabalho, eles ganham ainda maior efetividade. Com outra linguagem, foi isso o que pensou Althusser ao falar na "reprodução das relações de produção" (ALTHUSSER, 1999).

Mas cabe, aqui, ressaltar um terceiro e último aspecto igualmente relevante para complexificar a ontologia do ser social por meio da linguagem, determinante para esta investigação. As imposições performativas estabelecidas pela linguagem nunca se fazem sem resistência. Se a linguagem permite uma maior amplitude e plasticidade no seu processo de constituição, ela é sempre disputada. É esse ambiente que suscita o que Lukács nomeia como o "duplo movimento em direções opostas" da linguagem. Nesse sentido, há sempre uma apropriação negativa nas objetividades produzidas pelo mundo social. Elas estão sempre sendo parcialmente negadas, contestadas, enfrentadas. E se o processo de imposição do signo se dá por uma relação de poder, o seu enfrentamento também o faz. Assim sendo, exige mecanismos também performativos de resistência.

Nesse contexto, o caráter heterogêneo da apropriação por Adorno do conceito de contradição ganha outra possibilidade explicativa. O ser social não se estabelece jamais como uma positividade perfeita, porque sempre atravessado por possibilidades que o negam, por um jogo complexo de positivações e negações, sempre historicamente reconstruídos, sempre em constante refazimento.

Isso faz do mundo social um ambiente sempre em disputa, sempre marcado por antagonismos. A objetividade que ele estabelece é sempre precária, porque ameaçada por outras

\footnotetext{
${ }^{5} \mathrm{O}$ caráter performativo da linguagem foi analisado, por exemplo, pela filósofa estadunidense Judith Butler para pensar como o gênero se constitui em nossos corpos e em nosso imaginário (BUTLER, 2010). Mas o alcance do conceito de performatividade vai além da perspectiva de gênero, e ganha nova materialidade se pensado ontologicamente.
} 
formas que lhe desafiam, e o amálgama que esse complexo produz é sempre instável e sempre difícil de ser apreendido ou determinado. Nesse sentido, categorias discursivas como formuladas por Laclau e Mouffe têm o importante papel de pôr em questionamento a cristalização discursiva de certos fatores supostamente objetivos do mundo social, que nem sempre consideram essa complexidade antagônica que os possibilita. Para além disso, permitem vislumbrar uma luta política como a articulação de grupos incomensuravelmente diferentes numa "rede de equivalências" que exige sempre uma constituição simbólica, não previamente determinada.

Essas categorias não são, certamente, suficientes. Elas perdem o seu poder de efetividade se não percebem que o mundo social se conforma objetivamente, constitui tendências, abarca o permanente desafio humano de produção e reprodução da vida em sua lida com a natureza, inclusive com a natureza da qual o próprio ser humano faz parte. $\mathrm{O}$ discursivo se constitui no trabalho e constitui o trabalho, num amálgama indissociável. E assim fazendo, constitui simultaneamente objetividades e negações/antagonismos a essas objetividades, projeta um horizonte de mundo e nega esses horizontes, estabelece relações de poder e concomitantes resistências ao poder. Trabalho e linguagem, mutuamente constituídos, propiciam a efetiva dialética do ser social, de um modo que sempre nos ultrapassa.

\section{REFERÊNCIAS BIBLIOGRÁFICAS}

ADORNO, Thedor W. Dialética negativa. Tradução de Marco Antonio Casanova. Rio de Janeiro: Zahar, 2009.

AUSTIN, John. Quando dizer é fazer. Tradução de Danilo Marcondes de Souza Filho. Porto Alegre: Artes Médicas, 1990.

ALTHUSSER, Louis. A favor de Marx. 2. ed. Tradução de Dirceu Lindoso. Rio de Janeiro: Zahar Editores, 1979.

ALTHUSSER, Louis. Sobre a reprodução. Tradução de Guilherme João de Freitas Teixeira. Petrópolis-RJ: Vozes, 1999.

ANDERSON, Perry. Las antinomias de Antonio Gramsci. Tradução de Lourdes Bassols e J. R. Fraguas. Mexico: Ed. Fontamara, 1991.

BUTLER, Judith. Problemas de gênero: feminismo e subversão da identidade. 3. ed. Tradução de Renato Aguiar. Rio de Janeiro: Civilização Brasileira, 2010.

GERAS, Norman. “Post-Marxism?”. New Left Review I/163, Maio/Junho 1987, pp. 44-82.

GERAS, Norman. "Ex-Marxism without substance: being a real reply to Laclau and Mouffe". New Left Review I/169, Maio/Junho 1988, pp. 34-61.

LACLAU, Ernesto. Nuevas reflexiones sobre la revolución de nuestro tiempo. Buenos Aires: Nueva Visión, 2000. 
LACLAU, Ernesto e MOUFFE, Chantal. "Post-Marxism without apologies". New Left Review I/166, Novembro/Dezembro 1987, pp. 79-106.

LACLAU, Ernesto e MOUFFE, Chantal. Hegemonia e estratégia socialista: por uma política democrática radical. Tradução de JoanildoBurity, Josias de Paula Jr. e Aécio Amaral. São Paulo: Ed. Intermeios, 2015.

LUKÁCS, Györg. Para uma ontologia do ser social II. Tradução de Nélio Schneider, Ivo Tonet e Ronaldo Vielmi Fortes. São Paulo: Boitempo, 2013.

LUKÁCS, Györg. Para uma ontologia do ser social I. 2. ed. Tradução de Carlos Nelson Coutinho, Mario Duayer e Nélio Schneider. São Paulo: Boitempo, 2018.

MARX, Karl. O Capital: crítica da economia política - Volume I - Livro primeiro, Tomo 1. Tradução de Regis Barbosa e Flávio R. Kohte. São Paulo: Nova Cultural. 1996.

MARX, Karl. Manuscritos econômico-filosóficos. Tradução de Jesus Ranieri. São Paulo: Boitempo, 2010.

MOUZELIS, Nicos. “Marxism or Post-marxism?”. New Left Review I/167, Janeiro/Fevereiro 1988, pp. 107-123.

SOMBRA, Laurenio Leite. "Identidade dos sujeitos: linguagem, constituição de sentido e valor". Revista Sísifo, no 1, Maio/Setembro 2015, pp. 95-114.

SOMBRA, Laurenio Leite. "Direito, interpretação e antagonismo: a disputa do sentido". In: ANDRADE DE SOUZA, Maria José, TORRES, Paulo Rosa e PITA, Flávia Almeira (Org.). O Direito e a educação do campo: experiências, aprendizagens, reflexões. Salvador: UEFS Editora, 2018. 